\title{
Wpływ rodzaju zanieczyszczenia powierzchni odlewu ze staliwa LH1 4 na jakość napoin wykonanych elektrodą otuloną
}

\author{
Influence of the type of surface contamination \\ of cast steel LH14 on the quality of padding welds \\ made by coated electrode
}

\begin{abstract}
Streszczenie
Napawanie jest szeroko stosowaną metodą naprawiania powierzchni. Pozwala między innymi na uzupełnienie miejsc, w których uprzednio wystąpiły wżery korozyjne. Techniki napawania wykorzystywane są również do przywracania pierwotnego kształtu zużytych części.

W pracy wykonano badania napoin wykonanych elektrodami otulonymi na czołowych powierzchniach cylindrycznych próbek ze staliwa LH14. Proces wykonywano dwoma rodzajami elektrod: Castolin 6601 (przeznaczoną do napawania staliwa) oraz Castolin Xuper NuceloTec 2222 (do łączenia elementów o dużych gabarytach wykonanych ze stali nierdzewnej, staliwa, bądź żeliwa). Niektóre powierzchnie przed wykonaniem procesu celowo zanieczyszczono, bądź napawano nieprawidłową techniką. Miało to na celu wywołanie niezgodności spawalniczych. Próbki poddano następnie badaniom wizualnym oraz penetracyjnym. Po badaniu penetracyjnym wykonano planowanie czoła na głębokość $1 \mathrm{~mm}$. Wynikało to z faktu, iż po naprawach regeneracyjnych następuje najczęściej usunięcie nadmiaru napawanego materiału. Następnie wykonano drugie badanie penetracyjne, które miało na celu wskazanie obecności ewentualnych niezgodności. Wykazano, iż próbki napawane elektrodą przeznaczoną do tego procesu miały o 35\% mniej niezgodności, niż wykonane elektrodą do spawania. Potwierdzono również, iż zanieczyszczenie powierzchni znacząco wpływa na powstanie niezgodności. Cześć z nich miała charakter powierzchowny i nie występowała po typowym dla tej metody naprawczej, usuwaniu nadmiaru materiału.
\end{abstract}

Słowa kluczowe: napawanie; elektrody otulone; odlew; badania nieniszczące

\begin{abstract}
Pad welding is one of the most common method to repair the surfaces. It helps to recover areas where corrosive wear occurred. It is also used as a method to restore the original shape of worn parts.

In this work pad welding on the face on cylindrical specimens of LH14 cast steel made by coated electrodes were carried. For process two types of electrodes were used - Castolin 6601 for pad welding of cast steel and Castolin Xuper NuceloTec 2222 for welding large components made of stainless steel, cast steel or cast iron. Some surfaces were contaminated before the process and others were welded by wrong technique to occur imperfections in specimens.

Than samples were subjected to visual and penetrant testing. After the penetrant testing, the forehead was $1 \mathrm{~mm}$ deep planned. This was due to the fact that after regeneration processes excess material is often removed. The second penetrant testing was then performed to demonstrate the presence of possible defects. It was found that the samples pad welded with the electrodes for pad welding have $35 \%$ less imperfections than the samples made by electrodes for welding. It has also been shown that surface contamination significantly affects to increase number of imperfections. Some of them were superficial and did not appear after the typical repair method, removing excess material.
\end{abstract}

Keywords: pad welding; covered electrodes; cast steel; nondestructive testing

Mgr inż. Jacek Tomków, dr inż. Jacek Haras - Politechnika Gdańska.

Autor korespondencyjny/Corresponding author: jacek.tomkow@pg.edu.pl 


\section{Wstęp}

Modyfikowanie powierzchni materiałów metalowych jest szeroko stosowanym zabiegiem w procesie wytwarzania i naprawiania maszyn $[1,2]$. Wśród metod regeneracji powierzchni najszersze zastosowanie znalazły natryskiwanie cieplne oraz napawanie $[3,4]$. Wynika to z faktu, że są one traktowane jako metody głównie naprawcze, pozwalające na regenerowanie zużytych części, bez konieczności ich wymiany, często bezpośrednio w środowisku pracy danej maszyny, bądź konstrukcji. W przypadku napawania stosuje się wiele technik spawalniczych. W obecnych czasach szerokie zastosowanie znajduje przetapianie powierzchni materiału z wykorzystaniem wysokowydajnych laserów [11]. Metodami wykorzystywanymi do regeneracji poprzez napawanie są również napawanie plazmowe [7], TIG [5], czy MIG [8]. Sam proces napawania znalazł zastosowanie $\mathrm{w}$ wielu gałęziach przemysłu. Można go spotkać w przemyśle cementowym, gdzie wykorzystuje się trudnościeralne warstwy napawane, narażone na oddziaływanie wysokich nacisków oraz występowanie dużego tarcia [9]. Proces ten wykorzystywany jest również ze względów ekonomicznych w przemyśle energetycznym w wymiennikach ciepła, które są eksploatowane w warunkach agresywnych chemicznie, np. w środowisku siarkowodoru, gdzie wykorzystuje się napawanie do wytworzenia warstw bimetalicznnych [10]. Napawanie wykorzystywane jest również szeroko do regeneracji zaworów silników okrętowych [11]. Stwierdzić można, iż procesy napawania zyskują coraz większe zastosowanie w konstrukcjach hydro- i oceanotechnicznych, zarówno podczas spawania na powietrzu, jak i w procesach realizowanych w środowisku wodnym [12].

Wynika to z faktu szerokiego stosowania materiałów odlewanych w takich konstrukcjach. Skutkowało to koniecznością powstania przepisów dotyczących stosowania materiałów odlewniczych, które zebrano w zaleceniach Okrętowych Towarzystw Klasyfikacyjnych, jak American Bureau of Shipping (ABS), czy Det Norske Veritas (DNV). W przepisach ABS zamieszczono zalecenia odnośnie materiałów, jakie można używać na konkretne wyroby. Przepisy te wyróżniają wytyczne m.in. na: elementy staliwne kadłubów statków; elementy staliwne wyposażenia statków; maszyny, kotły, elementy ciśnieniowe oraz rurociągi wykonane ze staliwa; maszyny, kotły, elementy ciśnieniowe oraz rurociągi wykonane z żeliwa oraz elementy maszynowe wykonane z brązu. Ponadto ściśle określono jakimi rodzajami badań należy te wyroby testować [13]. DNV skupia się przede wszystkim na zasadach przeprowadzania badań nieniszczących, tj. badań: wizualnych, penetracyjnych, prądami wirowymi, magnetycznoproszkowych, radiograficznych oraz ultradźwiękowych [14].

\section{Badania własne}

Celem badań było określenie wpływu rodzaju zanieczyszczenia powierzchni odlewu na wykrywalność niezgodności podczas badań nieniszczących. Ponadto dokonana została ocena jakości napoin wykonanych dwoma elektrodami o różnych przeznaczeniach. Do badań wykorzystano cylindryczne próbki wykonane ze staliwa LH 14. Skład chemiczny oraz właściwości mechaniczne tego materiału zaprezentowano w tablicy I. Próbki miały średnicę ok. $30 \mathrm{~mm}$, grubość $20 \mathrm{~mm}$ i były napawane ze średnimi wartościami natężeń prądu z zakresów zalecanych przez producenta elektrod.

Do napawania przygotowanych próbek użyto dwóch rodzajów materiałów dodatkowych. Pierwszym były rutylowo-zasadowe elektrody Castolin6601 o średnicy 2,5 mm. Elektrody przeznaczone są do spawania i napawania stali niestopowych oraz niestopowego staliwa. Drugim materiałem
Tablica I. Skład chemiczny i właściwości mechaniczne staliwa LH 14 Table I. Chemical composition and mechanical properties of LH 14 cast steel

\begin{tabular}{|c|c|c|c|}
\hline \multicolumn{4}{|c|}{ Skład chemiczny [\%] } \\
\hline C & Si & Mn & $\mathbf{P}$ \\
\hline $0,15 \div 0,30$ & $<0,7$ & $0,4 \div 0,8$ & $<0,035$ \\
\hline $\mathrm{s}$ & $\mathrm{Cr}$ & $\mathrm{Ni}$ & \\
\hline$<0,035$ & $12 \div 15$ & $<1$ & \\
\hline \multicolumn{4}{|c|}{ Własności mechaniczne } \\
\hline $\mathrm{Re}$ [MPa] & \multicolumn{2}{|c|}{$\mathrm{Rm}$ [MPa] } & $\mathrm{A}_{5}[\%]$ \\
\hline$>295$ & \multicolumn{2}{|c|}{$490 \div 690$} & $>15$ \\
\hline $\mathrm{Z}[\%]$ & \multicolumn{2}{|c|}{$\mathrm{KCU}\left[\mathrm{J} / \mathrm{cm}^{2}\right]$} & HB \\
\hline$>50$ & \multicolumn{2}{|c|}{30} & $140 \div 200$ \\
\hline
\end{tabular}

były elektrody w otulinie zasadowej Castolin Xuper NucleoTec 2222 o średnicy 3,2 mm, przeznaczone do łączenia elementów o znacznych gabarytach wykonanych ze stali nierdzewnej, staliwa, bądź żeliwa. Właściwości zastosowanych materiałów dodatkowych zaprezentowano w tablicy II.

Tablica II. Właściwości mechaniczne zastosowanych materiałów dodatkowych

Table II. Mechanical properties of filler materials

\begin{tabular}{|c|c|c|c|}
\hline \multicolumn{4}{|c|}{ Elektroda Castolin 6601 E 38 0 RC 11} \\
\hline Re [MPa] & $\mathrm{Rm}[\mathrm{MPa}]$ & $\mathrm{A}_{5}[\%]$ & $\mathrm{KCU}\left[\mathrm{J} / \mathrm{cm}^{2}\right]$ \\
\hline$>380$ & $>470$ & 20 & 47 \\
\hline \multicolumn{4}{|c|}{ Elektroda Castolin Xuper NucleoTec 2222 E Ni 1} \\
\hline $\operatorname{Re}[\mathrm{MPa}]$ & $\mathrm{Rm}[\mathrm{MPa}]$ & $\mathrm{A}_{5}[\%]$ & $\mathrm{KCU}\left[\mathrm{J} / \mathrm{cm}^{2}\right]$ \\
\hline$\sim 390$ & $\sim 670$ & 45 & 130 \\
\hline
\end{tabular}

\section{Wykonanie napoin}

Próbki napawano wedle planu zaprezentowanego w tablicy III. Miał on na celu późniejszą ocenę wpływu sposobu zanieczyszczenia napawanej powierzchni oraz wykazanie ewentualnych różnic podczas wykonywania procesu różnymi materiałami dodatkowymi.

W przypadku użycia elektrod Castolin 6601 stosowano prąd stały u biegunowości ujemnej o natężeniu $80 \mathrm{~A}$, za wyjątkiem próbki 11, gdzie zastosowano prąd o natężeniu $60 \mathrm{~A}$ (poniżej zaleceń producenta), natomiast w przypadku Castolin Xuper NucleoTec 2222 prąd o natężeniu $100 \mathrm{~A}$.

Podczas wykonywania napoin napotkano na liczne problemy. Najczęstszym była trudność w zajarzeniu łuku, co wystąpiło dla próbek pokrytych tłuszczem, topnikiem do spawania metodą SAW, warstwą wody, farbą z markera oraz dla próbki ze zbyt małymi parametrami prądowymi. Ponadto nastąpił problem ze stabilnością jarzenia się łuku spawalniczego podczas procesu (próbki 5, 6, 11, 13 i 14). W przypadku próbki pokrytej topnikiem lutowniczym, zajarzenie łuku nastąpiło po bardzo wielu próbach, a sam łuk odchylał się podczas napawania, czemu towarzyszyły również liczne rozpryski. Duże problemy pojawiły się także dla próbki pokrytej pastą miedzianą, która uległa zapłonowi, co znacznie ograniczało widoczność i utrudniało prowadzenie procesu. W pozostałych przypadkach proces przebiegał stabilnie. 
Tablica III. Plan wykonania próbek

Table III. Specimens plan of pad welding

\begin{tabular}{|c|c|c|}
\hline Nr próbki & Warunki napawania & Elektroda \\
\hline 1 & wykonana prawidłowo & Castolin 6601 \\
\hline 2 & wykonana prawidłowo & Castolin Xuper NucleoTec 2222 \\
\hline 3 & nieoszlifowana & Castolin 6601 \\
\hline 4 & nieoszlifowana & Castolin 6601 \\
\hline 5 & pokryta smarem & Castolin Xuper NucleoTec 2222 \\
\hline 6 & pokryta smarem & Castolin 6601 \\
\hline 7 & po napawaniu włożona do wody & Castolin Xuper NucleoTec 2222 \\
\hline 8 & po napawaniu włożona do wody & Castolin 6601 \\
\hline 9 & pokryta topnikiem do spawania metodą SAW 2222 \\
\hline 10 & pokryta topnikiem do spawania metodą SAW & Castolin Xuper NucleoTec 2222 \\
\hline 11 & zbyt niska wartość natężenie prądu & Castolin 6601 \\
\hline 12 & pokryta warstwą wody wodociągowej & Castolin 6601 \\
\hline 13 & pokryta topnikiem lutowniczym & Castolin 6601 \\
\hline 14 & pokryta farbą z markera & Castolin 6601 \\
\hline 15 & pokryta pastą miedzianą & Castolin 6601 \\
\hline
\end{tabular}

Po napawaniu próbki poddano badaniom nieniszczącym. W pierwszej kolejności wykonane zostały badania wizualne wg PN-EN ISO 17637:201 1 [15]. Następnie wykonano dwie serie badań penetracyjnych wg PN-EN ISO 3452-1:2013-08 [16]. W pierwszej badano napoiny, przed drugą wykonano planowanie powierzchni na głębokość $1 \mathrm{~mm}$. Wynikało to z faktu, iż po naprawach regeneracyjnych następuje najczęściej usunięcie nadmiaru napawanego materiału.

\section{Wyniki badań wizualnych}

Badania wizualne ujawniły występowanie wielu niezgodności na napawanych próbkach. Najczęściej występującymi były otwarte powierzchniowo pęcherze oraz przyklejenia. Przykładowe wyniki badań wizualnych przedstawiono na rysunku 1. W tablicy IV zaprezentowano zestawienie wyników badań wizualnych.

\section{Wyniki badań penetracyjnych}

Przeprowadzono dwie serie badań penetracyjnych. Jedna bez obróbki napoiny, druga po planowaniu czoła na głębokość $1 \mathrm{~mm}$. W wielu przypadkach wykazano, iż wskazania ujawnione w pierwszej serii zostały uwidocznione również po przeprowadzonej obróbce. Jest to jednoznaczne z faktem, iż niezgodności miały charakter nie tylko powierzchniowy, ale pojawiały się w głębi napawanego materiału. Zrealizowane badania wykazały obecność przyklejeń oraz pęcherzy w większości próbek. Brak wskazań po planowaniu czoła zanotowano w próbkach wykonanych prawidłową techniką oraz w próbce, którą pokryto topnikiem lutowniczym, mimo iż podczas jej wykonywania zajarzenie łuku spawalniczego przysporzyło najwięcej problemów. Przykładowe wyniki badań penetracyjnych przedstawiono na rysunku 2. W tablicy $V$ zaprezentowano zestawienie wyników badań penetracyjnych.

Tablica IV. Wyniki badań wizualnych

Table IV. Results of visual testing

\begin{tabular}{|c|c|c|c|}
\hline $\begin{array}{c}\mathrm{Nr} \\
\text { próbki }\end{array}$ & Wykryte niezgodności & Warunki napawania & Elektroda \\
\hline 1 & brak & wykonana prawidłowo & Castolin 6601 \\
\hline 2 & pęknięcie 3 mm & wykonana prawidłowo & $\begin{array}{l}\text { Castolin Xuper } \\
\text { NucleoTec } 2222\end{array}$ \\
\hline 3 & otwarte powierzchniowo pęcherze & nieoszlifowana & Castolin 6601 \\
\hline 4 & otwarte powierzchniowo pęcherze & nieoszlifowana & $\begin{array}{l}\text { Castolin Xuper } \\
\text { NucleoTec } 2222\end{array}$ \\
\hline 5 & nierówność lica o długości 3 mm & pokryta smarem & Castolin 6601 \\
\hline 6 & $\begin{array}{l}\text { otwarty powierzchniowo pęcherz, } \\
\text { przyklejenie na } 40 \% \text { długości krawędzi }\end{array}$ & pokryta smarem & $\begin{array}{l}\text { Castolin Xuper } \\
\text { NucleoTec } 2222 \\
\end{array}$ \\
\hline 7 & otwarte powierzchniowo pęcherze & po napawaniu włożona do wody & Castolin 6601 \\
\hline 8 & $\begin{array}{l}\text { wypłynięcie napoiny poza próbkę, otwarte powierzchniowo } \\
\text { pęcherze, poprzeczne pęknięcie na } 80 \% \text { szerokości napoiny }\end{array}$ & po napawaniu włożona do wody & $\begin{array}{l}\text { Castolin Xuper } \\
\text { NucleoTec } 2222\end{array}$ \\
\hline
\end{tabular}


CD. Tablica IV. Wyniki badań wizualnych

Cont. Table IV. Results of visual testing

\begin{tabular}{|c|c|c|c|}
\hline $\begin{array}{c}\text { Nr } \\
\text { próbki }\end{array}$ & Wykryte niezgodności & Warunki napawania & Elektroda \\
\hline 9 & $\begin{array}{c}\text { nierówność lica o długości 2 mm, } \\
\text { przyklejenie na 15\% długości krawędzi }\end{array}$ & $\begin{array}{c}\text { pokryta topnikiem do spawania metodą } \\
\text { SAW }\end{array}$ & Castolin 6601 \\
\hline 10 & $\begin{array}{c}\text { otwarte powierzchniowo pęcherze, } \\
\text { przyklejenie na 15\% długości krawędzi }\end{array}$ & pokryta topnikiem do spawania metodą & $\begin{array}{c}\text { Castolin Xuper } \\
\text { SucleoTec 2222 }\end{array}$ \\
\hline 11 & $\begin{array}{c}\text { nierówność lica, otwarte powierzchniowo pęcherze, } \\
\text { przyklejenie na 15\% długości krawędzi }\end{array}$ & zbyt niska wartość natężenia prący & Castolin 6601 \\
\hline 12 & nierówność lica & pokryta warstwą wody wodociągowej & Castolin 6601 \\
\hline 13 & nierówność lica, przyklejenie na 20\% długości krawędzi & pokryta topnikiem lutowniczym & Castolin 6601 \\
\hline 14 & otwarte powierzchniowo pęcherze, pęknięcia lica & pokryta farbą z markera & Castolin 6601 \\
\hline 15 & otwarte powierzchniowo pęcherze, & pokryta pastą miedzianą & Castolin 6601 \\
\hline
\end{tabular}

a)

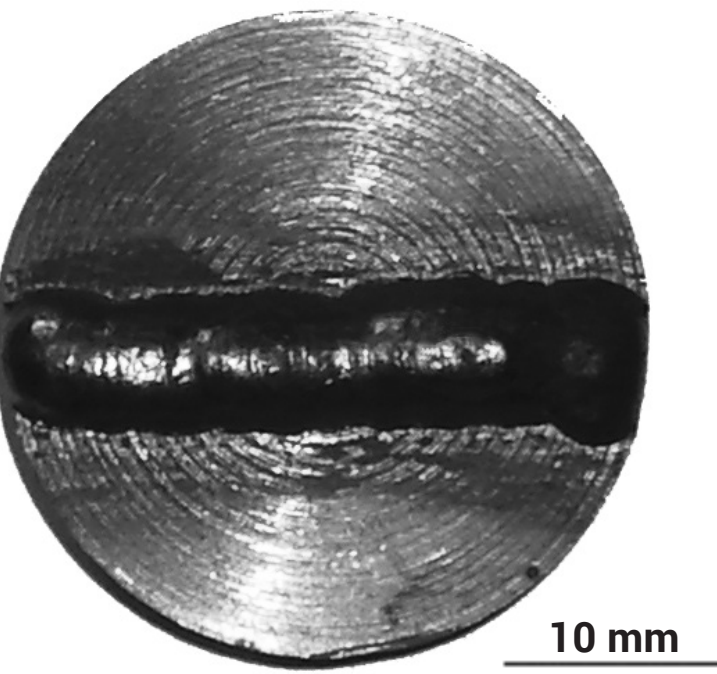

c)

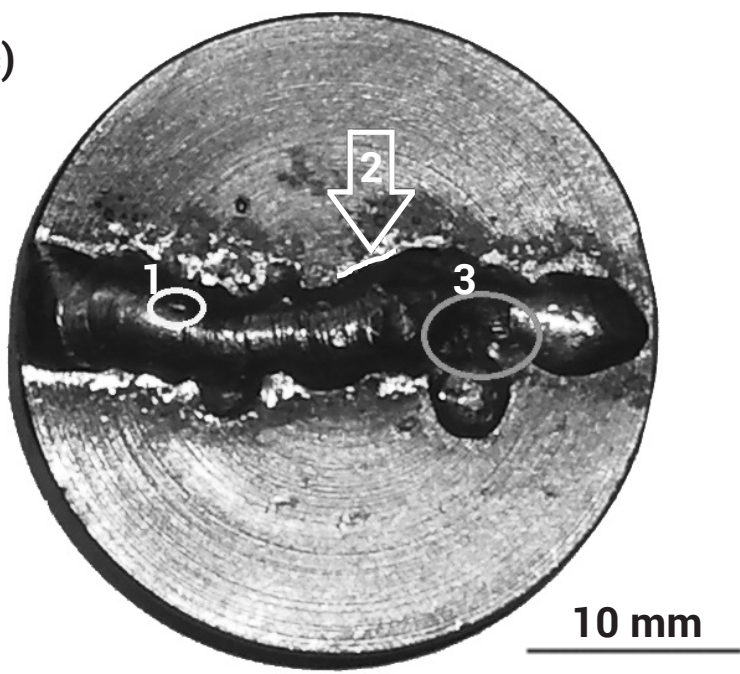

b)

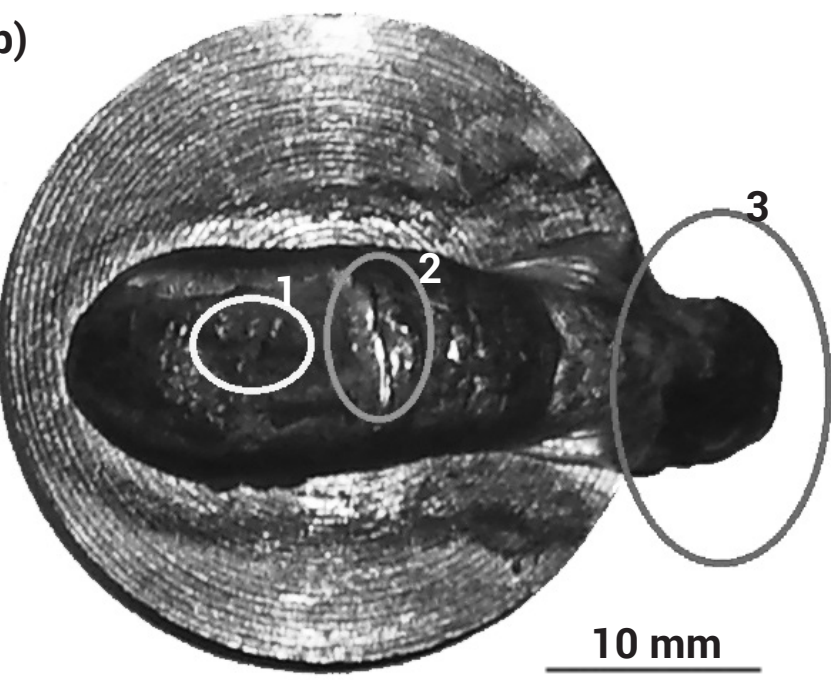

d)

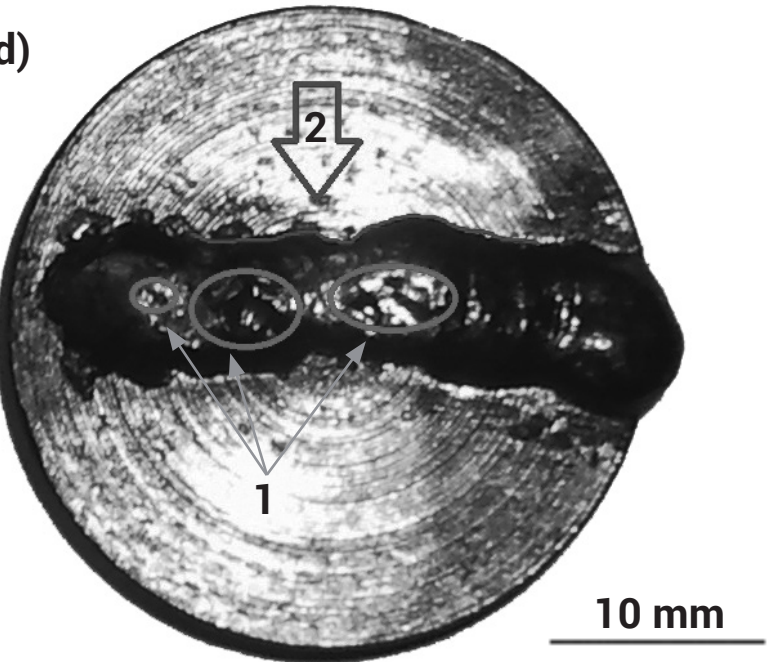

Rys. 1. Przykładowe wyniki badań wizualnych: a) próbka 1 (wykonana prawidłowo), brak niezgodności - Castolin 6601; b) próbka 8 (gwałtownie chłodzona), wypłynięcie napoiny poza próbkę, wynikające z błędu spawacza (3), otwarte powierzchniowo pęcherze (1), poprzeczne pęknięcie na 80\% szerokości napoiny (2) - Castolin Xuper NucleoTec 2222; c) próbka 11 (zbyt niska wartość natężenia prądu), wklęśnięcie lica (1), otwarte powierzchniowo pęcherze (3), przyklejenie o długości $2 \mathrm{~mm}$ (2) - Castolin 6601; d) próbka 15 (pokryta pastą miedzianą), otwarte powierzchniowo pęcherze (1), przyklejenie na 70\% długości krawędzi (2) - Castolin 6601

Fig. 1. Exemplary results of the visual testing: a) sample 1 (done correctly), no imperfections - Castolin 6601; b) sample 8 (rapidly cooled), outflow of the padding weld outside of the sample because of the welder's mistake (3), surface open blisters (1), transverse crack on $80 \%$ of the width of the weld (2) - Castolin Xuper NucleoTec 2222; c) sample 11 (too low current value), incompletely filled groove (1), surface open blisters (3), incomplete fusion on the length of $2 \mathrm{~mm}$ (2) - Castolin 6601; d) sample 15 (covered with copper paste), surface open blisters (1), incomplete fusion on $70 \%$ of the edge length (2) - Castolin 6601 

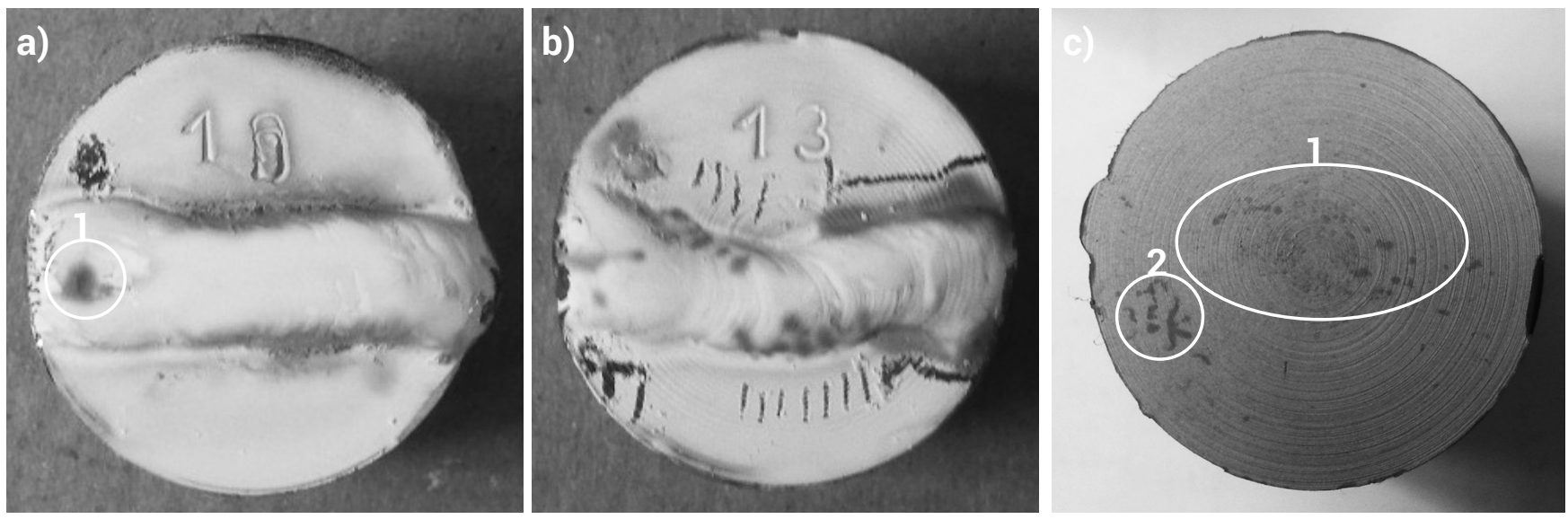

Rys. 2. Wyniki badań penetracyjnych, przed obróbką lica: a) próbka 10 (pokryta topnikiem do spawania metodą SAW), otwarte powierzchniowo pęcherze (1), przyklejenie na 60\% długości krawędzi - Castolin Xuper NucleoTec 2222; b) próbka 13 (pokryta topnikiem lutowniczym), otwarte powierzchniowo pęcherze, przyklejenie na 35\% długości krawędzi - Castolin 6601; po obróbce lica: c) próbka 10, przyklejenie (1), wada wewnętrzna odlewu (2)

Fig. 2. Results of penetration tests, before face deep planed: a) sample 10 (covered with SAW welding flux), surface open blisters (1), incomplete fusion on $60 \%$ of the edge length - Castolin Xuper NucleoTec 2222; b) sample 13 (covered with solder flux), surface open blisters, incomplete fusion on $35 \%$ of the edge length - Castolin 6601; after face deep planed: c) sample 10, incomplete fusion (1), internal defect of casting (2)

Tablica V. Wyniki badań penetracyjnych Table V. Results of penetrant testing

\begin{tabular}{|c|c|c|c|c|}
\hline $\begin{array}{c}\mathrm{Nr} \\
\text { próbki }\end{array}$ & Wykryte niezgodności przed obróbką lica & $\begin{array}{l}\text { Wykryte niezgodności po } \\
\text { obróbce lica }\end{array}$ & Warunki napawania & Elektroda \\
\hline 1 & brak & brak & wykonana prawidłowo & Castolin 6601 \\
\hline 2 & $\begin{array}{l}\text { otwarte powierzchniowo pęcherze } \\
\text { i przyklejenie }\end{array}$ & brak & wykonana prawidłowo & $\begin{array}{l}\text { Castolin Xuper } \\
\text { NucleoTec } 2222\end{array}$ \\
\hline 3 & $\begin{array}{l}\text { otwarte powierzchniowo pęcherze, } \\
\text { przyklejenie na } 50 \% \text { długości krawędzi }\end{array}$ & przyklejenie & nieoszlifowana & Castolin 6601 \\
\hline 4 & $\begin{array}{c}\text { skupisko otwartych powierzchniowo } \\
\text { pęcherzy }\end{array}$ & pęcherze & nieoszlifowana & $\begin{array}{l}\text { Castolin Xuper } \\
\text { NucleoTec } 2222\end{array}$ \\
\hline 5 & przyklejenie na $15 \%$ długości krawędzi & przyklejenie & pokryta smarem & Castolin 6601 \\
\hline 6 & $\begin{array}{l}\text { otwarte powierzchniowo pęcherze, } \\
\text { przyklejenie na } 30 \% \text { długości krawędzi }\end{array}$ & przyklejenie & pokryta smarem & $\begin{array}{l}\text { Castolin Xuper } \\
\text { NucleoTec } 2222\end{array}$ \\
\hline 7 & przyklejenie na 15\% długości krawędzi & przyklejenie & $\begin{array}{l}\text { po napawaniu włożona } \\
\text { do wody }\end{array}$ & Castolin 6601 \\
\hline 8 & $\begin{array}{l}\text { otwarte powierzchniowo pęcherze, } \\
\text { przyklejenie na } 100 \% \text { długości krawędzi }\end{array}$ & przyklejenie, pęcherze & $\begin{array}{l}\text { po napawaniu włożona } \\
\text { do wody }\end{array}$ & $\begin{array}{l}\text { Castolin Xuper } \\
\text { NucleoTec } 2222\end{array}$ \\
\hline 9 & przyklejenie na 50\% długości krawędzi & przyklejenie, pęknięcia & $\begin{array}{c}\text { pokryta topnikiem } \\
\text { do spawania metodą SAW }\end{array}$ & Castolin 6601 \\
\hline 10 & $\begin{array}{l}\text { otwarte powierzchniowo pęcherze, } \\
\text { przyklejenie na } 60 \% \text { długości krawędzi }\end{array}$ & przyklejenie & $\begin{array}{c}\text { pokryta topnikiem } \\
\text { do spawania metodą SAW }\end{array}$ & $\begin{array}{l}\text { Castolin Xuper } \\
\text { NucleoTec } 2222\end{array}$ \\
\hline 11 & $\begin{array}{l}\text { otwarte powierzchniowo pęcherze, } \\
\text { przyklejenie na } 50 \% \text { długości krawędzi }\end{array}$ & przyklejenie & $\begin{array}{l}\text { zbyt niska wartość } \\
\text { natężenia prądu }\end{array}$ & Castolin 6601 \\
\hline 12 & Przyklejenie na 20\% długości krawędzi & przyklejenie & $\begin{array}{l}\text { pokryta warstwą wody } \\
\text { wodociągowej }\end{array}$ & Castolin 6601 \\
\hline 13 & $\begin{array}{l}\text { otwarte powierzchniowo pęcherze, } \\
\text { przyklejenie na } 35 \% \text { długości krawędzi }\end{array}$ & brak & $\begin{array}{l}\text { pokryta topnikiem } \\
\text { lutowniczym }\end{array}$ & Castolin 6601 \\
\hline 14 & Przyklejenie na 60\% długości krawędzi & przyklejenie & pokryta farbą z markera & Castolin 6601 \\
\hline 15 & $\begin{array}{l}60 \% \text { powierzchni lica zawierające pęknięcia } \\
\text { oraz otwarte powierzchniowo pęcherze, } \\
\text { przyklejenie na } 90 \% \text { długości krawędzi }\end{array}$ & przyklejenie, pęcherze & pokryta pastą miedzianą & Castolin 6601 \\
\hline
\end{tabular}




\section{Podsumowanie i wyniki}

Podczas badania porównawczego napoin wykonanych różnymi elektrodami zauważono, iż napoiny wykonane na zanieczyszczonych powierzchniach posiadały znaczną ilość niezgodności. Zaobserwowano negatywny wpływ braku szlifowania, oczyszczenia próbki z tłuszczu, czy obecności topnika do spawania metodą SAW. Jak wykazały badania nieniszczące, do powstawania niezgodności przyczyniły się również: niewłaściwe prowadzenie elektrody, zbyt niska wartość natężenia prądu spawania, znajdujące się na napawanej powierzchni: topnik lutowniczy, farba markera oraz pasta miedziana. Ponadto dokonano oceny zastosowanego materiału do napawania i wykazano, iż mniej niezgodności wykryto w przypadku napoin wykonanych elektrodą otuloną, przeznaczoną m.in. do realizacji tego procesu. Zrealizowane badania pozwoliły na sformułowanie poniższych wniosków:

1. Napoiny wykonane elektrodą Castoli 6601 (przeznaczoną do napawania staliwa) miały o 35\% mniej niezgodności, niż te wykonane elektrodą Castolin Xuper NuceloTec 2222 (do łączenia elementów o dużych gabarytach wykonanych ze stali nierdzewnej, staliwa, bądź żeliwa).

2. Zanieczyszczenia powierzchni takie, jak tłuszcze, farba markera, topniki, pasta miedziana negatywnie wpłynęły na jakość otrzymanych napoin. Badania nieniszczące (VT i PT) zlokalizowały szereg rozległych niezgodności.

3. Wskazania w badaniach penetracyjnych wykonanych przed i po obróbce lica różniły się w wielu miejscach. Świadczy to o tym, iż wiele zlokalizowanych niezgodności miało charakter powierzchniowy.

4. Badania wizualne nie mogą być jedynym kryterium oceniania przydatności napoin regeneracyjnych w staliwie stopowym. Dla stwierdzenia poprawności wykonania danej napoiny należy wykonać szereg badań nieniszczących.

\section{Literatura}

[1] Chmielewski T.: Projektowanie procesów technologicznych - Spawalnictwo, Oficyna Wydawnicza Politechniki Warszawskiej, Warszawa 2013.

[2] Chmielewski T., Golański D.: Znaczenie spawalnictwa w procesie remanufacturingu, Przegląd Spawalnictwa 6/2011.

[3] Znamirowski Z., Kozerski S., Łatka L., Pawłowski L.: Wpływ przygotowania powierzchni na elektronową emisję polową powłok $\mathrm{TiO}_{2}$ natryskanych plazmowo z zawiesin, Przegląd Spawalnictwa 3/2015

[4] Smoleńska H., Kończewicz W., Łabanowski J.: Regeneracja zaworów silników okrętowych metodą napawania plazmowego, Przegląd Spawalnictwa 9/2011.

[5] Kik T., Górka J., Czupryński A., Martyniszyn A.: Napawanie krawędzi przedmiotów metodami TIG i PTA, Przegląd Spawalnictwa 9/2011.

[7] Pfeifer T., Czwórnóg B.: The effect of plasma surfacing parameters on the geometry and structure of overlay welds, Institute of Welding Bulletin 4/2015.

[8] Skorupa A., Góral T.: Wpływ technologicznych parametrów napawania na geometrię napoin z brązu układanych na podłożu stalowym metodą MIG, Przegląd Spawalnictwa 3/2012.
[9] Bęczkowski R., Gucwa M.: Kwalifikowanie napawania warstw trudnościeralnych pracujących w warunkach przemysłu cementowego, Przegląd Spawalnictwa 9/2015.

[10] Rogalski G., Fydrych D., Prokop-Strzelczyńska K.: Napawanie austenitycznym drutem proszkowym elementów wymiennika ciepła, Przegląd Spawalnictwa 1/2017.

[11] Smoleńska H., Łabanowski J., Kończewicz W.: Regeneration of marine engine valves using laser surfacing, Welding International 2/2016.

[12] Rogalski G., Łabanowski J., Fydrych D., Tomków J.: Bead-On-Plate Welding on S235JR Steel by Underwater Local Dry Chamber Process, Polish Maritime Research 1/2014.

[13] ABS „Rules for materials and welding 2011. Part 2"

[14] DNV Classification notes No. 7 "Non-destructive testing. December 2004”

[15] PN-EN ISO 17637:2011 Badania nieniszczące złączy spawanych. Badania wizualne złączy spawanych.

[16] PN-EN ISO 3452-1:2013-08 Badania nieniszczące. Badania penetracyjne. Część 1:Zasady ogólne. 